\title{
Evaluation of resistance to temephos insecticide in Culexpipiens pipiens larvae collected from three districts of Tunisia
}

\author{
Ahmed Tabbabi ${ }^{1,2+}$, Jabeur Daaboub ${ }^{1,2+}$, Ali Laamari ${ }^{1}$, Raja Ben Cheikh ${ }^{1}$, Mohamed Feriani ${ }^{1}$, \\ Chokri Boubaker ${ }^{1}$, Ibtissem Ben Jha ${ }^{1}$, Hassen Ben Cheikh ${ }^{1}$
}

1. Laboratory of Genetics, Faculty of Medicine of Monastir, University of Monastir, Tunisia.

2. Department of Hygiene and Environmental Protection, Ministry of Public Health, Tunisia.

${ }^{+}$Ahmed Tabbabi and Jabeur Daaboub contributed equally to this work.

\begin{abstract}
Background: Mosquitoes are considered as the main groups of arthropods that cause nuisance and public health problems.

Objectives: Evaluation of resistance to temephos insecticide in Culex pipiens pipiens larvae collected from three districts of Tunisia.

Methods: Late third and early fourth instars larvae of Culex pipiens pipiens were collected in three localities of Northern and Southern Tunisia. Field collected populations were tested against temephos insecticide and compared to bioassays of a susceptible reference strain. The cross-resistance between temephos and propoxur, and the polymorphism of over-produced esterases and AChE 1 were investigated.

Results: Studied populations exhibited tolerance to temephos with low and high levels of resistance. The resistance ratio $\left(\mathrm{RR}_{50}\right)$ values of temephos ranged from 1.34 to 114 . Synergists and starch electrophoresis showed that the metabolic resistances were involved in the recorded resistance. Likewise, the resistant target site (acetyl cholinesterase: AChE 1) was responsible for the recorded resistance to temephos compound in Culex pipiens pipiens.

Conclusion: The low and high resistance recorded to temephos insecticides is particularly interesting, because it leaves a range of tools useable by vector control services. However, further studies are needed to determine its spread and anticipate vector control failure where these insecticides are used.
\end{abstract}

Keywords: Culex pipiens pipiens, temephos resistance, Tunisia.

DOI: https://dx.doi.org/10.4314/ahs.v19i1.8

Cite as: Tabbabi A, Daaboub J, Laamari A, Cheikh RB, Feriani M, Boubaker C, Jha IB, Cheikh HB. Evaluation of resistance to temephos insecticide in Culex pipiens pipiens (Diptera: Culicidae) larvae collected from three districts of Tunisia. Afri Health Sci. 2019;19(1): 1361-1367. https:// dx.doi.org/10.4314/abs.v19i1.8

\section{Introduction}

Mosquitoes including Culex pipiens are responsible for several serious diseases and able to transmit diseases
Corresponding author:
Ahmed Tabbabi,
Laboratory of Genetics,
Faculty of Medicine of Monastir,
University of Monastir,
Monastir, Tunisia.
Email: tabbabiahmed@gmail.com

agents infecting over 600 million people per year ${ }^{1,2}$. Culex pipiens pipiens are known by their ecologic plasticity which explains their wide geographical distribution (temperate and tropical regions). This species may be the cause of strong nuisance and can transmit several parasitosis such as the Japanese Encephalitis, the West Nile fever ${ }^{3-6}$, the Rift Valley virus and certain filariasis ${ }^{7-11}$. Culexpipiens mosquito has been strongly suspected as the most likely vector in the transmission of West Nile virus outbreaks that have affected Tunisia ${ }^{12-15}$ in 1997, 2003, 2007, 2010, 2011 and 2012. This situation forces us to investigate one of the major obstacles to vectors disease control, the mos- 
quito resistance to insecticides since the use of chemical insecticides for mosquito control remains the most widespread.

In general, resistance to organophosphates including temephos insecticides can be metabolic or due to target site modifications. For target-site resistance, several authors have been identified and reported a relatively small number of highly conserved point mutations in the gene encoding the acetylcholinesterase (AChE) enzyme of many species $^{16,17}$. For metabolic resistance, other studies on a range of insect species identified and reported genomic changes which lead to gene amplification, over expression and/or modification of genes encoding members of the glutathione S-transferases (GSTs), cytochrome P450 (CYTP450) and carboxylesterases (CEs) ${ }^{18}$. Unfortunately, the massive use of insecticides during the malaria eradication program between 1967 and 1978 led to the development of strong resistance worldwide in Culex pipiens from Tunisia ${ }^{19-22}$. The aim of the present study was to evaluate the status of temephos resistance in larval populations of Culex pipiens pipiens (Diptera: Culicidae) in Tunisia and estimate the involved mechanisms using different synergists. The cross-resistance between temephos and propoxur, and the polymorphism of over-produced esterases and AChE 1 were also investigated.

\section{Methods}

Standard methods of Raymond et al. ${ }^{23}$ were performed on larvae populations of Culex pipiens pipiens mosquitoes collected in three breeding sites in northern and Southern Tunisia (Figure 1). Identification of collected populations was done morphologically using the key of Brunhes et $\mathrm{al}^{24}$. Collected larvae were transported to the laboratory and directly transferred into plastic trays containing distilled water with rabbit croquette which served as food under standard insectary conditions $\left(25 \pm 1^{\circ} \mathrm{C}\right.$ and $70 \pm$ $5 \% \mathrm{RH})$. Bioassays were performed on both early third and late fourth instars. However, young larvae were reared until advanced instars. Field collected strains were tested against temephos insecticide and compared to bioassays of a susceptible reference strain. Five concentrations of temephos $(100,10,1,0,1,0,01 \mathrm{ppm})$ providing between 0 and $100 \%$ mortality were used in a total volume of $100 \mathrm{ml}$ of water containing $1 \mathrm{ml}$ of ethanol solution of the tested insecticide. The tests were replicated five times per concentration. In each replicate, 20 early third and late fourth instar larvae were released. After a period of 24 hours, larval mortality was recorded. The Mazzarri and Georghiou ${ }^{25}$ criteria were followed to classify the resistance level of each population tested as follows: low $(R R<5)$, moderate $(5 \leq R R \leq 10)$ or high $(R R>10)$. We assessed also the effect of the synergists piperonyl-butoxide $(\mathrm{Pb})$ on metabolic insecticide resistance. Esterase's activities were characterized on homogenates of adult thorax and abdomen according to the method of Pasteur et al. ${ }^{26}$. Propoxur bioassays which included one dose $(1 \mathrm{mg} / \mathrm{l})$ was done to estimate the common mechanism of resistance to temephos insecticide: acetylcholinesterase resistance. According the method described by Bourguet et al. ${ }^{27}$, AChE1 polymorphism was analyzed to comparing AChE1 activity of homogenates of adult heads in the absence or presence of propoxur. Three phenotypes including ace-1R, ace-1S alleles, and duplicated haplotype were separated using this enzyme bioassay. The obtained results were analyzed by using the log probit program of Raymond $^{28}$, based on Finney ${ }^{29}$ to obtain $\mathrm{LC}_{50}, \mathrm{LC}_{95}$ and regression line. 


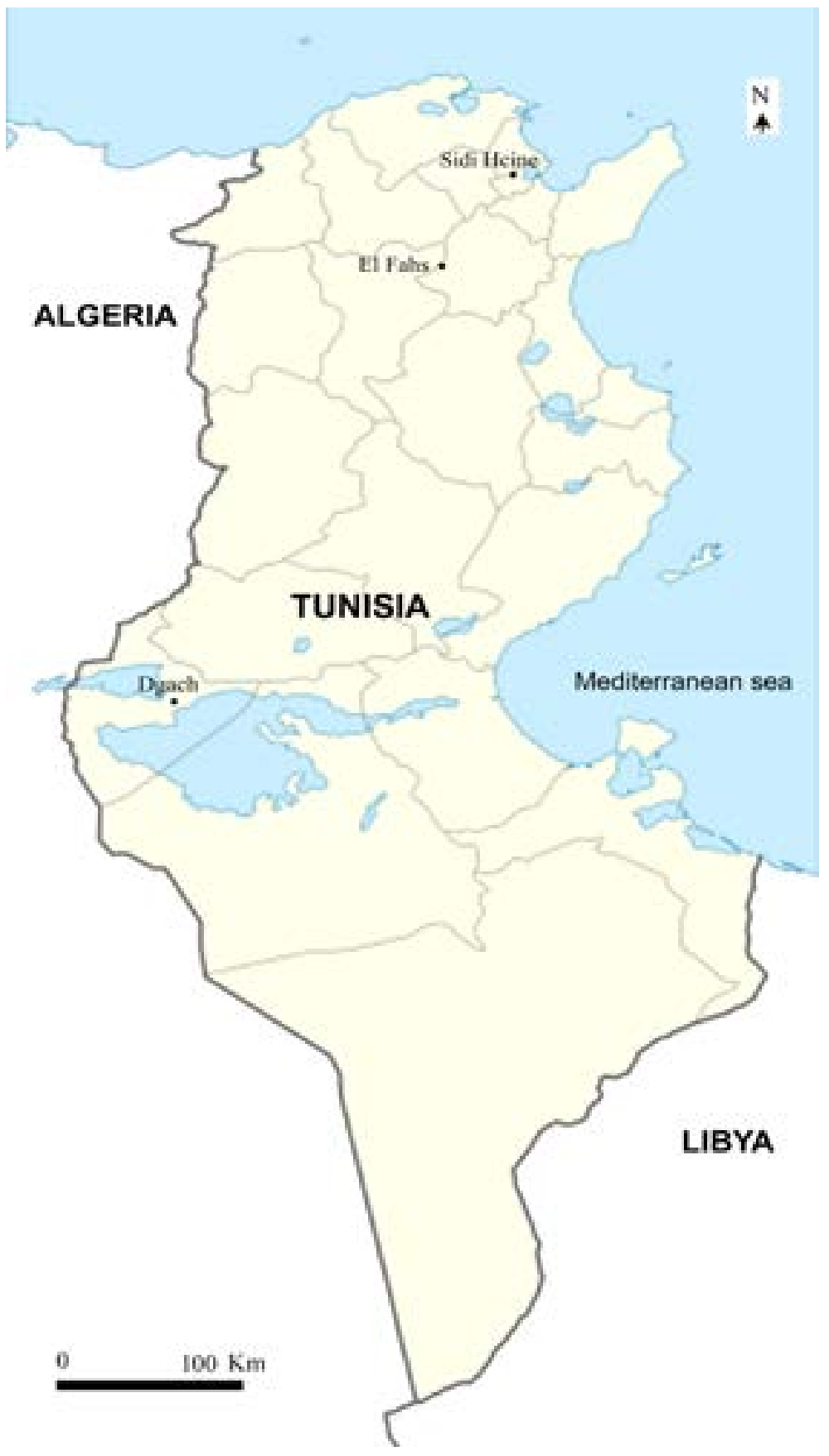

Figure 1: Geographic origin of Tunisian populations

\section{Results}

The resistance to temephos insecticide in field populations of Culexpipiens pipiens are presented in Table 1. The resistance ratio $\left(\mathrm{LC}_{50}\right)$ values of temephos ranged from 1.34 to 114 and showed their low and high levels according Mazzarri et al ${ }^{25}$ criteria. 
Table 1: Temephos resistance characteristics of Tunisian Culexpipienspipiens

\begin{tabular}{|c|c|c|c|c|c|c|c|c|c|c|c|c|c|}
\hline \multirow[t]{3}{*}{ Population } & \multicolumn{3}{|c|}{ Temephos } & \multicolumn{5}{|c|}{ Temephos +DEF } & \multicolumn{5}{|c|}{ Temephos +Pb } \\
\hline & $\mathrm{LC}_{50}$ in $\mu \mathrm{g} / \mathrm{I}$ & Slope & $\mathrm{RR}_{50}$ & $\mathrm{LC}_{50}$ in $\mu \mathrm{g} / \mathrm{l}$ & Slope & $\mathrm{RR}_{50}$ & $\mathrm{SR}_{50}$ & RSR & $\mathrm{LC}_{50}$ in $\mu \mathrm{g} / \mathrm{l}$ & Slope & $\mathrm{RR}_{50}$ & $\mathrm{SR}_{50}$ & RSR \\
\hline & (a) & $\pm \mathrm{SE}$ & (a) & (a) & $\pm \mathrm{SE}$ & (a) & (a) & & (a) & \pm SE & (a) & (a) & \\
\hline Slab & $\begin{array}{c}1,2 \\
(1,1-1,4)\end{array}$ & $\begin{array}{c}2,34 \\
\pm 0,22\end{array}$ & - & $\begin{array}{c}0,32 \\
(0,28-0,36)\end{array}$ & $\begin{array}{c}, 99 \\
\pm 0,69\end{array}$ & - & $\begin{array}{c}3,84 \\
(2,89-5,09)\end{array}$ & - & $\begin{array}{c}2,2 \\
(1,7-2,8)\end{array}$ & $\begin{array}{c}1,94 \\
\pm 0,28\end{array}$ & - & $\begin{array}{c}0,56 \\
(0,44-0,72)\end{array}$ & - \\
\hline 1- Sidi Hcine & $\begin{array}{c}142 \\
(65,5-308)\end{array}$ & $\begin{array}{c}2,41 \\
\pm 0,75^{* *}\end{array}$ & $\begin{array}{c}114 \\
(60,2-216)\end{array}$ & - & - & - & - & - & $\begin{array}{c}7,3 \\
(3-17)\end{array}$ & $3,44 \pm 2,48^{* *}$ & $\begin{array}{c}3,32 \\
(1,12-9,84)\end{array}$ & $\begin{array}{c}19,4 \\
(6,00-63,0)\end{array}$ & 34,33 \\
\hline 2-El Fahs & $\begin{array}{c}3,1 \\
(2,1-4,4)\end{array}$ & $\begin{array}{c}1,69 \\
\pm 0,31\end{array}$ & $\begin{array}{c}2,55 \\
(1,93-3,37)\end{array}$ & - & - & - & - & - & - & - & - & - & - \\
\hline 3-Dgach & $\begin{array}{c}1,6 \\
(0,98-2,8)\end{array}$ & $\begin{array}{c}2,05 \\
\pm 0,35\end{array}$ & $\begin{array}{c}1,34 \\
(0,87-2,05)\end{array}$ & - & - & - & - & - & - & - & - & - & - \\
\hline
\end{tabular}

(a), $95 \% \mathrm{Cl}$ ** Parallelism test positif but without probability.

$\mathrm{RR}_{50}$, resistance ratio at $\mathrm{LC}_{50}\left(\mathrm{RR}_{50}=\mathrm{LC}_{50}\right.$ of the population considered $/ \mathrm{LC}_{50}$ of Slab); $\mathrm{SR}_{50}$, synergism ratio $\left(\mathrm{LC}_{50}\right.$ observed in absence of synergist $/ \mathrm{LC}_{50}$ observed in presence of synergist) $\mathrm{RR}$ and $\mathrm{SR}$ considered significant $(\mathrm{P}<0.05)$ if their $95 \% \mathrm{Cl}$ did not include the value 1 .

$\mathrm{RSR}$, relative synergism ratio (RR for insecticide alone / $\mathrm{RR}$ for insecticide plus synergist).

The addition of $\mathrm{Pb}$ synergist in sample \# 1 increased the toxicity to used insecticide (RSR $>30$ ), indicating that the resistance mechanisms inhibited by synergist (CYTP450) were involved in the resistance of the studied sample. Starch electrophoresis was realized to verify the involvement of detoxification (esterase) in the recorded resistance because it was not possible to do all synergists bioassays mainly DEF synergist. Two esterases were detected in the most resistant sample with high frequency of A4-B4 (45\%). Three esterases including A4-B4, B12 and $\mathrm{C} 1$ were revealed in sample \# 2 with low frequencies. Low frequencies of two esterases including A4-B4 and C1 were reported in sample \# 3 which showed the lowest level of resistance to temephos and propoxur.

Cross-resistance temephos/propoxur was detected using bioassays and the mortality due to propoxur was significantly correlated with the $\mathrm{LC}_{50}$ of temephos insecticide indicating the resistance of the common target site: AChE 1. The propoxur mortality was low in the most resistant population (32\%). The high moralities, 38\% and $99 \%$, were associated to the susceptibility of samples \# 2 and 3 , respectively. The polymorphism of AChE 1 showed that the highest frequencies of acetylcholinesterase 1 (AChE 1) resistant phenotypes was recorded in the most resistant population (sample \# 1) with a percentage of $74 \%$ including an important percentage of duplicate phenotype [RS]. However, the highest frequencies of acetylcholinesterase 1 (AChE 1) susceptible phenotypes was reported in the two susceptible populations (samples \# 2 and 3) with a percentages of 80 and $75 \%$, respectively.

\section{Discussion}

Unfortunately, the massive use of insecticides during the malaria eradication program between 1967 and 1978 has led to the development of strong resistance worldwide in Culex pipiens from Tunisia ${ }^{19-22}$. Furthermore, organophosphates actually remain one of the major tools for culicinae control including Culex pipiens. It is clear that closer collaboration between resistance experts in agriculture and public health is needed. Indeed and despite the absence of agricultural control in the studied areas, we can consider that the migration including passive transportation of mosquitoes and gene flow play major roles in the dispersion of resistance genes between distant populations ${ }^{30}$. Except the previous and ancient studies of Ben Cheikh and his collaborators ${ }^{19-22,31}$, there are no previous published studies about the resistance status of Tunisian Culex pipiens pipiens populations to chemical insecticides. Therefore, these populations of Culex pipiens pipiens need to be monitored for insecticide resistance in this area. Previous findings ${ }^{19-22,31}$ showed that organophosphate and carbamate resistance was widespread in Tunisian populations of Culex pipiens. Ben Cheikh et al ${ }^{19}$ showed low resistance ratio levels of Culex pipiens pipiens to temephos insecticide, not exceeding 10-fold. However, high resistance level of this species to temephos was recorded in Tunisia and reached 400 -fold ${ }^{31}$.

The use of studied insecticides in public health explained the recorded resistance of Culexpipiens pipiens. Carbamate and organophosphate resistance was strongly correlated with the presence of an insensitive acetylcholinesterase which results in reduced sensitivity to inhibition of the enzyme. This target site resistance has been found and documented in many vectors including Culex pipiens and other mosquitoes ${ }^{19,32-34}$. In Benin, a cross-resistance between organophosphatess (fenitrothion) and carbamates (bendiocarb and propoxur) in Anopheles gambiae was reported with the presence of insensitive acetylcholines- 
terase $^{35}$. The polymorphism of AChE 1 showed that the highest frequencies of acetylcholinesterase 1 (AChE 1) resistant phenotypes was recorded in the most resistant population with an important percentage of duplicate phenotype [RS]. This could be probably due to the fitness costs associated to different alleles. Indeed, the overall fitness advantage of the duplicated haplotype may result from a much lower fitness cost $\mathrm{t}^{36}$.

Esterases, CYTP450 and glutathione-S-transferases are the three detoxification enzymes known to confer resistance to insecticides in mosquitoes vectors for all major classes of insecticides currently used for vector control, including organochlorine, organophosphates, carbamates, and pyrethroids. In the present study, synergist bioassays and biochemical characterization showed that esterases and CYTP450 were involved in the recorded resistance. Our results are in agreement with previous studies on the role of the CYTP450, esterases and the glutathione-S-transferases in the organophosphate including temephos resistance ${ }^{19,37,38}$. However, authors showed that AChE 1 identified above is known to be a dominant feature in resistance insects ${ }^{39}$.

\section{Conclusion}

In the present study, both resistant target site and detoxification enzymes were identified and therefore confer the recorded resistance to temephos and propoxur compounds in Culex pipiens pipiens. The selection pressure for resistance could have risen mainly from the use of these insecticides in agriculture, as well as in public health. Given the increase of resistance to temephos insecticide in Culex pipiens pipiens compared to previous studies, there is an urgent need for field and laboratory monitoring of insecticide resistance.

\section{Acknowledgements}

This work was kindly supported by the Ministry of Higher Education and Scientific Research of Tunisia by funds allocated to the Research Unit (Génétique 02/UR/0803) and by DHMPE of the Minister of Public Health of Tunisia. We are very grateful to $\mathrm{S}$. Ouanes, for technical assistance, A. Ben Haj Ayed and I. Mkada for help in bioassays, S. Saïdi, Tunisian hygienist technicians for help in mosquito collecting, and M. Nedhif and M. Rebhi for their kind interest and help.

\section{Conflict of interest}

The authors declare that they have no conflict of interest.

\section{References}

1. Kolberg R. Finding sustainable ways to present Parasitic Diseases. Science. 1994; 264:1859-1861. PubMed.

2. OMS. Unicef, World Malaria Report 2005. Roll Back Malaria. Genève. OMS; 2005; 292.

3. Turell MJ, O'Guinn ML, Dohm DJ, Jones JW. Vector competence of North American mosquitoes (Diptera: Culicidae) for West Nile Virus. J. Med. Entomol. 2001; 38: 130-134.

4. CDC. Provisional surveillance summary of the West Nile Virus epidemic. United States Morbidity and Mortality Weekly Report 2002; 51: 1129-1133.

5. Pelah D, Abramovich Z, Maarkus A, Wiesman Z. The use of commercial saponin form Quillaja sdponaria bark as a natural larvicidal agent Aedes aegypti and Culex pipiens. J. Ethnopharmacol. 2002; 81: 407- 409. PubMed.

6. Krida G, Diancourt L, Bouattour A, Rhim A, Chermiti B, Failloux AB. Assessment of the risk of introduction to Tunisia of the Rift Valley fever virus by the mosquito Culex pipiens. Bull. Soc. Pathol. Exot. 2011; 104: 250-259. PubMed.

7. Harb M, Faris R, Gad AM, Hafez ON, Ramzi R, Buck AA. The resurgence of lymphatic filariasis in the Nile Delta. Bulletin WHO. 1993; 71: 49-54. PubMed.

8. Krida G, Bouattour A, Rodhain F, Failloux AB. Variability among Tunisian populations of Culex pipiens: genetic structure and susceptibility to a filarial parasite, Brugia pahangi. Parasitol. Res. 1998; 84: 139-142. PubMed.

9. Vinogradova EB. Culex pipiens pipiens Mosquitoes: Taxonomy, Distribution, Ecology, Physiology, Genetics, Applied Importance and Control. Sofia, Bulgaria, Pensoft. Publishers. 2000; $250 \mathrm{p}$.

10. Abdel-Hamid YM, Soliman MI, Allam KM. Spatial distribution and abundance of culicine mosquitoes in relation to the risk of filariasis transmission in El Sharqiya Governorate, Egypt. Egypt. Acad. J. biolog. Sci. 2009; 1: 3948. PubMed.

11. Abdel-Hamid YM, Soliman MI, Kenawy MA. Mosquitoes (Diptera: Culicidae) in relation to the risk of disease transmission in El Ismailia governorate, Egypt. J. Egypt. Soc. Parasitol. 2011; 41: 109-118. PubMed.

12. Triki H, Murri S, Le Guenno B, Bahri O, Hili K, Sid- 
hom M, Dellagi K. West Nile viral meningo-encephalitis in Tunisia. Medecine Tropicale. 2001; 61: 487-490.

13. Hachfi W, Bougmiza I, Bellazreg F, Bahri O, Kaabia N, Bahri F, Letaief A. Second epidemic of West Nile virusmeningoencephalitis in Tunisia. Med. Mal. Infect, 2010; 40: 456-461.

14. Bouatef S, Hogga N, Ben Dhifallah I, Triki H, Ben Alya Bouafif N, Achour N. Monitoring and current situation of meningitis andmeningo-encephalitis to West Nile virus in Tunisia. Tun. Rev. Infect, 2012; 6: 181-182.

15. Riabi S, Gaaloul I, Mastouri M, Hassine M., and Aouni M. An outbreak of WestNile virus infection in the region of Monastir Tunisia. 2003. Pathog. Global Health. 2014; 108: 148-157.

16. Dianhao G, Jiapeng L, Yuenan Z, Huamei X, Kang H, Chuanlin Y, Jianhua X, Fei L. ACE: an efficient and sensitive tool to detect insecticide resistance-associated mutations in insect acetylcholinesterase from RNA-Seq data. BMC Bioinformatics. 2017; 18:330.

17. Samia Elfekih, Matthew Shannon, Julien Haran, Alfried P. Vogler. Detection of the Acetylcholinesterase Insecticide Resistance Mutation (G328A) in Natural Populations of Ceratitis capitata. J Economic Entomology. 2014; 107(5):1965-1968.

18. Yanola J, Chamnanya S, Lumjuan N, Somboon P. Insecticides resistance in the Culex quinquefasciatus populations from northern Thailand and possible resistance mechanisms. Acta Trop. 2015; 149:232-8

19. Ben Cheikh H, Haouas-Ben Ali Z, Marquine M, Pasteur N. Resistance to organophosphorus and pyrethroid insecticides in Culex pipiens (Diptera: Culicidae) from Tunisia. J Med Entomol. 1998; 35: 251-260.

20. Pasteur N, Marquine M, Ben Cheikh H, Bernard C, Bourguet D. A new mechanism conferring unprecedented high resistance to chlorpyrifos in Culex pipiens (Diptera : Culicidae). J Med Entomol. 1999; 36: 794-802.

21. Daaboub J, Ben Cheikh R, Lamari A, Ben Jha I, Feriani $\mathrm{M}$, Boubaker $\mathrm{C}$, Ben Cheikh $\mathrm{H}$. Resistance to pyrethroid insecticides in Culex pipiens pipiens (Diptera: Culicidae) from Tunisia. Acta Trop. 2008; 107(1):30-6.

22. Tabbabi A, Daaboub J, Laamari A, Ben Cheikh R, Hassen Ben Cheikh. Pirimiphos-Methyl Resistance Status of Field Populations of Culex pipiens (Diptera: Culicidae) From Grand Tunis Area, Northeast Tunisia. Hered Genet. 2017; 6 (1).

23. Raymond M, Fournier D, Bride JM, Cuany A, Bergé J,
Magnin M, Pasteur N. Identification of resistance mechanisms in Culex pipiens (Diptera: Culicidae) from southern France: insensitive acetylchlinesterase and detoxifying oxidases. J Econ Entomol. 1986; 79: 1452-1458. PubMed.

24. Brunhes J, Rhaim A, Geoffroy B, Angel G, Hervy JP. [The mosquitoes of Mediterranean Africa CD-ROM of identification and teaching].1999. Edition IRD, Montpellier, France. Frensh.

25. Mazzarri MB, Georghiou GP. Characterization of resistance to organophosphate, carbamate, and pyrethroid insecticides in field populations of Aedes aegypti from Venezuela. J. Am. Mosq. Control Assoc. 1995; 11: 315-322. PubMed.

26. Pasteur N., Pasteur G., Catalan J., Bonhomme F., Britton-Davidian J., 1988. Practical isozyme genetics. Ellis Horwood, Chichester, United Kingdom.

27. Bourguet D., Pasteur N., Bisset J. Raymond M. Determination of ace1 genotypes in single mosquitoes: toward an ecumenical biochemical test. Pest Biochem Physiol. 1996; 55, 122-128.

28. Raymond M, Prato G, Ratsira D. PROBIT. Analysis of mortality assays displaying quantal response. 1993; Praxeme (Licence No. L93019), Saint Georges d'Orques, France.

29. Finney D. J., 1971. Probit analysis. Cambridge University Press, Combridge.

30. Chareonviriyaphap T, Aum-aung B, Ratanatham S. Current insecticide resistance patterns in mosquito vectors in Thailand. SouthEast Asian J Trop Med Public Health. 1999; 30(1):184-194.

31. Daaboub J, Tabbabi A, Lamarai A, Ben Cheikh R, Bel Hadj Ayed A, Ben Cheikh H. Susceptibility of field-collected mosquitoes (Culex pipiens) in northern Tunisia to temephos an organophosphate insecticide. HAsian Pac J Health Sci. 2017; 4(2): 157-161.

32. Halim Zahid Safi N, Ali Ahmadi A, Nahzat S, Payman Ziapour S, Hassan Nikookar S, Fazeli-Dinan M, Enayati A, Hemingway J. Evidence of metabolic mechanisms playing a role in multiple insecticides resistance in $A n o p h$ eles stephensi populations from Afghanistan. Malar J. 2017; 16: 100 .

33. Du W, Awolola TS, Howell P, Koekemoer LL, Brooke BD, Benedict MQ, Coetzee M, Zheng L. Independent mutations in the $\mathrm{Rdl}$ locus confer dieldrin resistance to Anopheles gambiae and An. arabiensis. Insect Mol Biol. 2005; 14(2):179-183.

34. Wondji CS, Dabire RK, Tukur Z, Irving H, Djouaka 
$\mathrm{R}$, Morgan JC. Identification and distribution of a GABA receptor mutation conferring dieldrin resistance in the malaria vector Anopheles funestus in Africa. Insect Biochem Mol Biol. 2011; 41(7):484-491.

35. Aikkpon R, Agossa F, Ossè R, Oussou O, Aïzoun N, Oké-Agbo F, Akogbéto M. Bendiocarb resistance in Anopheles gambiae s.l. populations from Atacora department in Benin, West Africa: a threat for malaria vector control. Parasit Vectors. 2013; 6:192.

36. Labbé P, Berthomieu A, Berticat C, Alout H, Raymond M, Lenormand T, Weill M. Independent duplications of the acetylcholinesterase gene conferring insecti- cide resistance in the mosquito Culexpipiens. Mol Biol Evol. 2007; 24: 1056-1067.

37. Bisset JA, Rodriguez MM, Diaz C, Soca A. Course of insecticide resistance in Culex quinquefasciatus (Diptera: Culicidae) in a region of La Habana. Rev Cubana Med Trop. 2000; 52: 180-185.

38. Liu H, Xu Q, Zhang L, Liu N. . Chlorpyrifos resistance in mosquito Culex quinquefasciatus. J Med Entomol. 2005; 42: 815-820.

39. Assogba BS, Djogbénou LS, Milesi P, Berthomieu A, Perez J, Ayala D, Chandre F, Makoutodé M, Labbé P, Weill. M. An ace-1 gene duplication resorbs the fitness cost associated with resistance in Anopheles gambiae, the main malaria mosquito. Sci Rep. 2015; 5: 14529. 